\title{
Psychiatry
}

\section{New Trends in Management of Epilepsy in Patients with Cerebral Venous Malformations: Our Experience}

\author{
Ivan P. Artyukhov ${ }^{1}, \mathrm{PhD}, \mathrm{ScD}$; Diana V. Dmitrenko ${ }^{1 *}, \mathrm{PhD}, \mathrm{ScD}$; \\ Natalia A. Shnayder ${ }^{1}, \mathrm{PhD}, \mathrm{ScD}$; Ekaterina V. Gurenova ${ }^{1}$; \\ Alexander A. Molgachev ${ }^{2}$; Olga S. Shilkina ${ }^{1}$; Evgenia A. Dontceva ${ }^{1}, \mathrm{PhD}$ \\ ${ }^{1}$ Krasnoyarsk State Medical University \\ ${ }^{2}$ Krasnoyarsk Diagnostic-Treatment Center of International Institution of Biological Systems \\ Krasnoyarsk, the Russian Federation
}

\begin{abstract}
Background: Venous vascular malformations, also known as venous angiomas or, more exactly, developmental venous anomalies (DVAs), represent congenital, anatomically variant pathways in the normal venous drainage of the brain area. In general neurological practice, DVAs are not considered epileptogenic, therefore, in conducting neuroimaging as a rule, not taken into account. A positive correlation, however, between the location of DVAs and the electroencephalographic seizure focus is debated.

Materials and Methods: The present study provides a complete analysis of clinical and MRI characteristics of symptomatic epilepsies associated with cerebral venous malformations in children and adults. Patients were selected after a retrospective search through the database of the University Clinic into which, since 2016, patients were prospectively entered. To date (February 2016), there is a total of 5,856 patients with epilepsy of which there are 105 patients with congenital malformations of the brain, and 32 of them were found to have principal diagnosis of DVA.

Results: Cavernous angiomas prevailed among venous anomalies (53.1\%); DVAs were registered in $46.9 \%$ of cases. The associated analysis of DVA localization and the epileptic seizure types showed a direct relationship in $60.0 \%$ cases.

Conclusion: DVAs as a cause of seizures are important to consider when examining patients with epileptic seizures. (Int J Biomed. 2016;6(3):207-212.).
\end{abstract}

Key Words: brain • developmental venous anomalies • cavernous malformation • epilepsy • management

\section{Abbreviations}

CM, cavernous malformation; CT, computed tomography; CVM, cerebral venous malformations; DVAs, developmental venous anomalies; GRE, gradient echo; ILAE, International League Against Epilepsy; MRI, magnetic resonance imaging; SGTCS, secondary generalized tonic-clonic seizures; SWI, susceptibility weighted imaging; VEM, video EEG monitoring.

\section{Introduction}

Cerebral venous malformations (CVMs), also known as venous angiomas or, more exactly, developmental venous anomalies (DVAs), represent congenital, anatomically variant

*Corresponding author: D. Dmitrenko, MD, ScD; Associate Professor of the Department of Medical Genetics and Brain Research of Postgraduate Education Institute, Krasnoyarsk State Medical University; Krasnoyarsk, Russia.E-mail: mart2802@yandex.ru pathways in the normal venous drainage of the brain area. They consist of converging dilated medullary veins that drain centripetally and radially into a transcerebral collector that opens either into the superficial subcortical or deep pial veins. ${ }^{[1]}$

DVAs have no proliferative potential, no direct arteriovenous shunts, and normal brain parenchyma between the dilated veins. ${ }^{[2]}$ Once thought to be rare, they are now considered to be the most common vascular malformations in the central nervous system (CNS). ${ }^{[3,4]}$ Although for many years DVAs were commonly called venous angiomas, the 
newer term DVA has been recommended as more appropriate because the involved vessels are not abnormally formed, but apparently merely dilated. The majority of DVAs are found occasionally and never cause symptoms, although there are isolated reports of patients with syndromes attributed to DVAs. For example, DVAs have been reported to cause epilepsy, progressive neurologic deficits, and haemorrhage. ${ }^{[5,6]}$ Chronic, often undetected, microhemorrhages of these lesions result in iron deposition in adjacent brain tissue in the form of hemosiderin, and the iron in this perilesional hemosiderin is thought to play a major role in their epileptogenicity. ${ }^{[7,8]}$ Frequently, convulsions have been associated with venous malformations. ${ }^{[9]}$ A positive correlation, however, between the location of DVAs and the electroencephalographic seizure focus is unusual.

Contrast-enhanced CT, which is no doubt responsible for the recent increase in the number of reported cases of DVAs, is yielding to the far superior imaging ability of magnetic resonance as it becomes routinely available. MRI is thus becoming the primary study medium of choice and the means by which diagnosis of DVAs is verified. ${ }^{[10]}$ Although the standard contrast-enhanced MRI is excellent in depicting DVAs, adjacent hemosiderin from associated cavernomas may not be assessed without the use of gradient-echo or echoplanar imaging, especially with fast spin-echo techniques. On a contrast-enhanced MRI, the cluster of veins in developmental venous anomalies has a spoke-wheel appearance; the veins are small at the periphery and gradually enlarge as they approach a central draining vein. ${ }^{[11]}$ GRE or T2* sequences are able to delineate these lesions better than T1 or T2 weighted images. In patients with familial or multiple cavernous angiomas, GRE $\mathrm{T} 2 *$ sequences are very important in identifying the number of lesions missed by conventional spin echo sequences. SWI may have sensitivity equal to that of GRE in detecting these capillary telangiectasias in the brain. SWI is also highly sensitive in detecting calcification as compared to T1 and T2 images. ${ }^{[12]}$

Epilepsy associated with cavernous angioma of the brain is widely recognized. However, in general neurological practice, DVAs are not considered epileptogenic: therefore, in conducting neuroimaging, as a rule they are not taken into account.

\section{Materials and Methods}

We analyzed clinical and MRI characteristics of symptomatic epilepsies associated with CVMs in children and adults. Patients were selected after a retrospective search through the database (October 2008 - February 2016) of the Neurological Center of Epileptology, Neurogenetics and Brain Research of the University Clinic into which, since 2016, patients were prospectively entered. To date (February 2016), there is a total of 5,856 patients with epilepsy of which there are 105 patients with congenital malformation of the brain, and 32 of them were found to have principal diagnosis of DVAs. We analyzed epidemiological variables such as age, gender, associated risk factors, clinical presentation, radiological data, treatment options, and follow-up. It was performed as a part of complex research No 210-16 «Epidemiological, genetic and neurophysiological aspects of nervous system disorders (central, peripheral, autonomic) and preventive medicine» (state registration No 0120.0807480). ${ }^{[13,14]}$ The present study was approved by the Ethics Committee of Krasnoyarsk State Medical University. Written informed consent was obtained from each patient.

From 2008 to 2016, we included 32 patients with CVMs and symptomatic epilepsy in our study. All patients underwent preliminary anamnestic and clinical selection using stratified randomization. All of the participants were residents of the Siberian Federal District, and had certain diagnosis of symptomatic epilepsy.

Symptomatic epilepsy diagnosis in all patients enrolled in this study was verified using VEM along with carrying out stress tests. All patients underwent brain MRI (1.5 Tesla or higher), including GRE T2* and SWI sequences. Detailed analysis of case history for each patient included debut age, the type of epileptic seizures at debut, and the dynamics of the disease progression.

All statistical analyses were carried out using licensed software package SPSS, version 20.0 (USA). Categorical variables are presented using frequencies and percentages The data for variation indices with nonparametric distribution are presented with medians and quartiles (Me [P25; P75]).

\section{Results}

Symptomatic epilepsies associated with CVMs were registered in $17(53.1 \%)$ male patients and in $15(46.9 \%)$ female patients. The age of patients at the time of the survey varied between 4 and 71 years with median of $27.5(17.5: 41.5)$ years; there were $8(25.0 \%)$ children and $24(75.0 \%)$ adults. The epilepsy onset age varied between 0.4 and 67 years with a median of 9.5 (5:26.5) years. Peak onset of the epileptic seizures varied between 0 and 10 years (17 [53.1\%]). The period from epilepsy onset to the brain MRI and DVA identification varied between 0 and 52 years with median of 5.5 (1:11) years.

Distribution of epilepsy seizure types was as follows: simple focal (partial) seizures in $18.8 \%$ of cases, complex focal (partial) seizures in 3.1\% of cases, combined simple and complex focal seizures in $18.8 \%$, SGTCS in $3.1 \%$, combined simple focal seizures and SGTCS in $15.6 \%$, both complex focal seizures and SGTCS in $21.3 \%$, and simple and complex focal seizures with SGTCS in $25 \%$ of cases.

Analysis of pedigrees identified 13 (40.6\%) patients with family members or close relatives presenting with congenital malformations and $5(15.6 \%)$ with epileptic seizures.

According to VEM-results, the location of the epileptic discharges was principally presented by frontal lobe seizures (13 [40.6\%]) and temporal lobe seizures (13 [40.6\%]).

The associated analysis of all CVM localization (by MRI) and location of the epileptic activity (by VEM) showed a direct relationship in $12(37.5 \%)$ cases, a partial relationship with one DVA in $6(18.8 \%)$ cases, and no associations in 14 $(43.8 \%)$ cases. The associated analysis of DVA localization and the epileptic seizure types showed a direct relationship in $9(60.0 \%)$ (Fig. 1 ) cases and no association in $6(40.0 \%)$ patients. In the latter group of patients, focal cortical dysplasia could serve as an area of beginning epileptic seizures. 


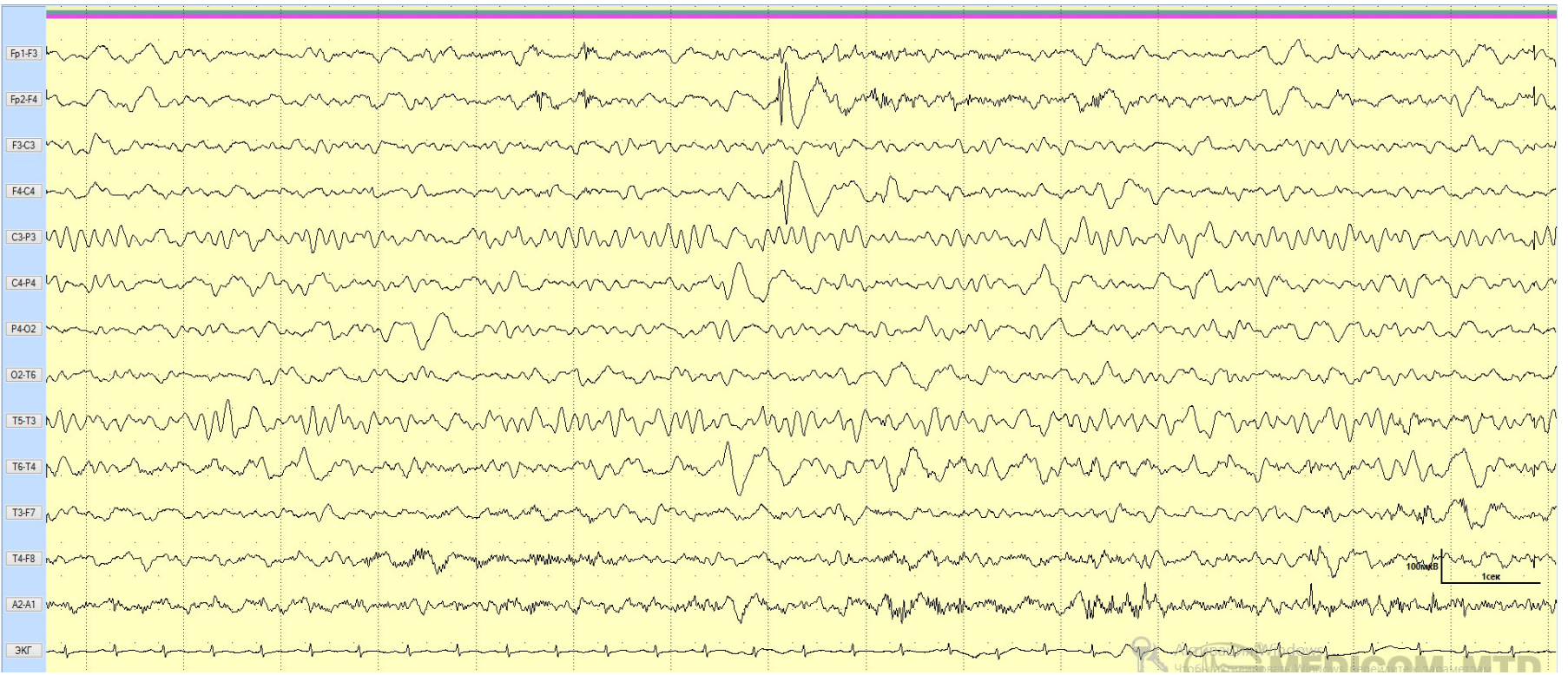

Fig. 1a. EEG of a 7-year-old girl: regional epileptiform activity in the right frontal lobe.

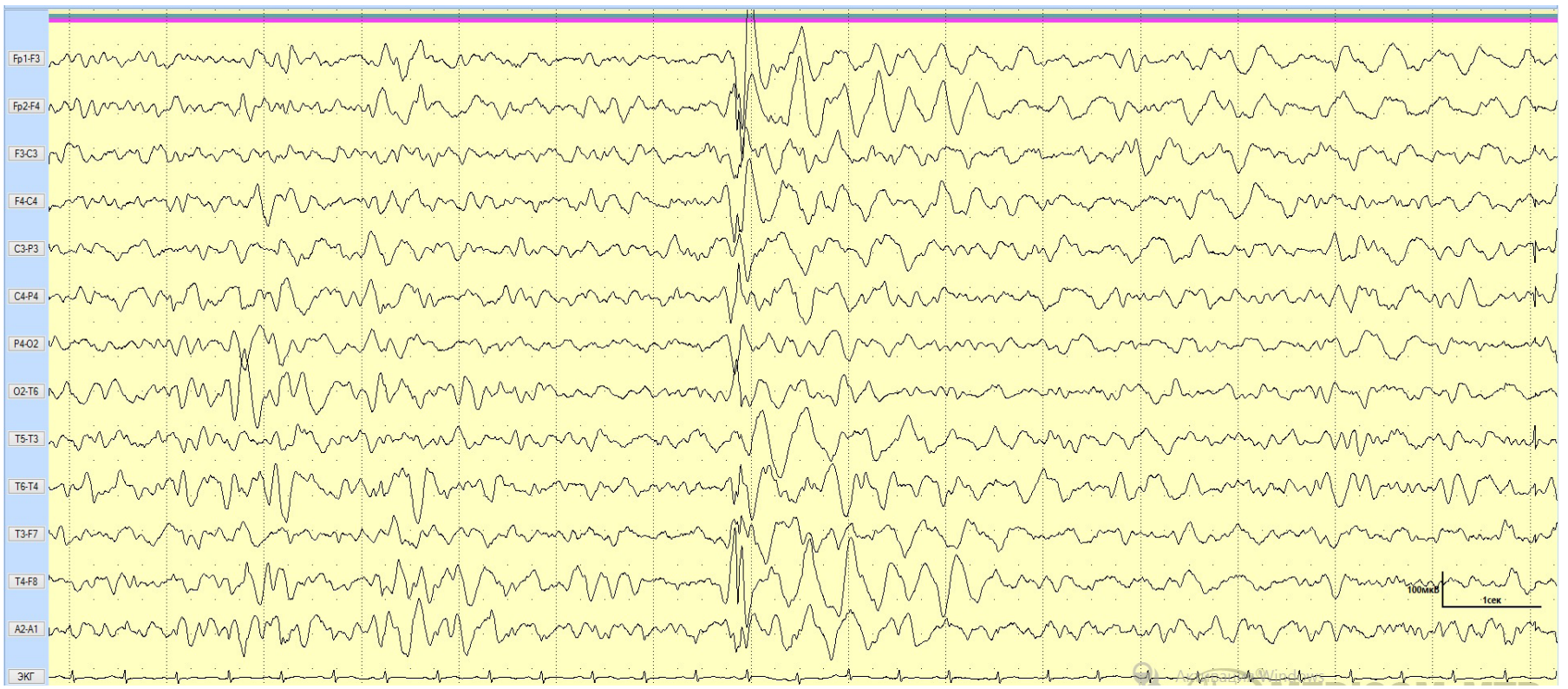

Fig. 1b. EEG of a 7-year-old girl: regional epileptiform activity in the right frontal lobe with secondary bilateral synchrony.

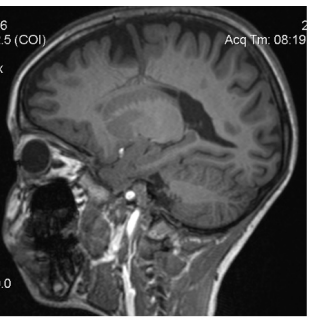

A

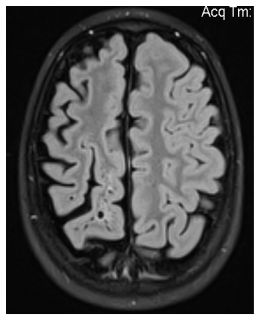

$\mathrm{B}$

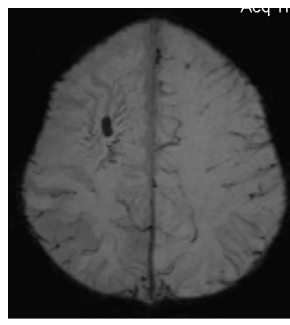

$\mathrm{C}$

Fig. 2. Brain MRI of a 7-year-old girl with symptomatic focal epilepsy associated with the isolated DVA.

(A). T1 sagittal image: venous angioma of the right frontal lobe involving massive superficial vein.

(B). T2 FLAIR image: atrophy of the right frontal lobe.

(C). SWI: venous angioma of the right frontal lobe.

Venous anomalies were detected in hereditary diseases such as Von Hippel-Lindau disease in $13(40.6 \%)$ patients, Sturge-Weber syndrome (encephalotrigeminal angiomatosis) in $2(6.2 \%)$ cases, Gorlin-Goltz syndrome in $3.1 \%$ cases, and tuberous sclerosis complex in $3.1 \%$ cases. Cerebral venous anomalies were isolated in 17 (53\%) cases (Fig. 2). Surgical treatment was recommended for focal epilepsy. Cavernous angiomas prevailed among venous anomalies (53.1\%); DVAs were registered in $46.9 \%$ of cases.

Monotherapy was administered in $78.1 \%$ cases; prevailing medications were carbamazepine group drugs (13 [52.0\%]). A drug-resistant epilepsy was observed only in $3(9.4 \%)$ cases of CVMs, including two cases of CM and one case of DVAs. 


\section{Discussion}

DVAs are extreme variations of normal transmedullary veins that are necessary for the drainage of the white and gray matter. ${ }^{[15]}$ Currently, due to progress in brain investigation, they can be diagnosed with a higher frequency. ${ }^{[16-20]}$

DVAs are the most commonly encountered vascular malformation in the CNS, accounting for up to $60 \%$ of them. Their prevalence is about $2.5 \%$ to $9 \%,{ }^{[21]}$ and they are usually solitary. DVA is a variation of normal venous drainage. It is considered to be formed during Padget's fourth to seventh stage of development.[22]

A typical venous angioma is composed of a large parent vein that receives an array of radially-oriented tributary veins in a spokewheel configuration which looks like «the caput medusa». ${ }^{[23]}$

It is generally accepted that DVAs are formed during intrauterine life, ${ }^{[24,25]}$ but no consensus exists regarding the mechanism leading to their formation. Their etiology and mechanism of development are unknown, but it is currently accepted that they act like a compensatory system of cerebral parenchyma venous drainage due to early failure, abnormal development, or an intrauterine occlusion of normal capillaries or small transcerebral veins and thrombosis of normal parenchymal veins. ${ }^{[22]}$ These drainage pathways may have developed as a method for maintaining the hemodynamic equilibrium of the transcortical venous drainage.

During embryogenesis, occlusion or maldevelopment occur during the formation of the medullary veins or their tributaries, and as a result, compensation DVA is formed. Thus, the main suggested etiology for DVA formation is an embryologic event that results in either arrested formation or thrombosis of the developing venous drainage of the specific region. ${ }^{[26-28]}$ That is followed by a secondary compensatory mechanism in which embryologic medullary venules persist and cluster locally in a large draining vein..$^{[27,29-31]}$ These might occasionally develop as a result of dominant inheritance of a gene mutation in the short arm of chromosome 9. ${ }^{[32]}$

DVAs can either drain into deep subependymal veins and the galenic system or drain into superficial cortical veins. The superficial pattern is present in about $70 \%$, while the deep drainage pattern is present in $20 \%$ of the population. ${ }^{[22,29,33]}$ The remaining $10 \%$ have a combination of the superficial and deep drainage. ${ }^{[22,29,33]}$ DVAs are mostly supratentorial and are found most frequently in the frontal lobe (36\% to $56 \%$ ) followed by the parietal (12\% to $24 \%)$, occipital $(4 \%)$ and the temporal lobes $(2 \%$ to $19 \%)$; in the cerebellum $(14 \%$ to $29 \%)$; in the basal ganglia (6\%); in the thalamus and ventricles $(11 \%)$, and in the brainstem (less than 5\%). ${ }^{[22,29,33]}$ DVAs may also be present adjacent to brain tumors, infarctions, demyelinating areas, and moyamoya malformations; also associated congenital anomalies of the cerebral arterial system, such as the primitive trigeminal artery, fetal origin of the posterior cerebral arterial system, as well as fetal venous anomalies, such as retention of the primitive facial, occipital, and marginal tentorial sinuses. ${ }^{[34]}$

The initial diagnosis is typically made in the third decade. ${ }^{[35,36]}$ There is an equal prevalence in men and women. Cerebral venous angioma is usually asymptomatic and may be found occasionally at autopsy or by angiography. ${ }^{[21,37]}$
DVAs may present with headache, seizure, dizziness, and ataxia. ${ }^{[35,38-40]}$ Prospective studies on venous angiomas have demonstrated a very low rate of both symptomatic hemorrhage $(0.34 \%$ per year) and neurologic symptoms; bleeding, when it rarely occurs, has been hypothetically blamed on putative neighboring cavernous malformations. ${ }^{[41]}$ Blood flow through venous angiomas is low, and they are thought to drain normally from the brain.

Symptoms can be produced either by venous congestion related to flow obstruction or mechanical compression (hydrocephalus or nerve compression). The clinical sequelae of DVA are likely related to the regional changes that occur near it. ${ }^{[42]}$ They reported histopathologic evidence of vascular remodeling related to altered hemodynamics in the region of DVA, including microvascular wall hyalinization and calcification, which are consistent with chronic regional blood flow alternation and venous hypertension. ${ }^{[43]}$

Very few cases have been reported in which DVAs were located in the same area as the EEG focus of the seizure. ${ }^{[39]}$ The incidence of seizures associated with symptomatic DVAs ranges from $8 \%$ to $29 \% \cdot{ }^{[35,44,45]}$ In most of the cases, DVAs were located in a different region with respect to the focus of the seizure ${ }^{[9,45]}$ or there was another lesion found that could be the cause of epilepsy. ${ }^{[38]}$ DVAs have been reported to be associated usually with generalized seizures, ${ }^{[44,46]}$ but some patients have experienced partial seizures, ${ }^{[44,47]}$ complex partial seizures ${ }^{[46]}$ or even Jacksonian march of motor seizures. ${ }^{[1]}$

Although cases of existence of DVAs and seizures have been reported, the correlation between them has not been firmly determined. ${ }^{[15,22,38,41,45]}$ The study of Striano et al. ${ }^{[15]}$ revealed that DVAs are rarely found in epileptic patients, as distinct from other vascular malformations, cavernomas in particular. Topographic and/or etiological relationships between DVA and epilepsy are still undefined. Similarly, seizures have been localized to areas not associated with DVA in several studies, ${ }^{[9,35]}$ or to associated cortical dysplasias. ${ }^{[15]}$

DVAs may be associated with abnormal neuronal migration and possible susceptibility to epileptogenesis. ${ }^{[39]}$ However, recent literature suggests that DVAs may be the cause of focal epilepsies in cases where no epileptogenic lesions can be detected. ${ }^{[48]}$ Several mechanisms are postulated based on the following: (1) subclinical hemorrhage, more likely when a DVA is associated with a cavernous malformation ${ }^{[9]}$ and (2) increased inflow or restricted outflow, resulting in intermittent cortical hyperemia and dysfunction creating an epileptic focus. ${ }^{[22]}$

Patients with DVAs associated with epilepsy require a precise analysis of the seizure pattern and EEG findings, because another epileptogenic lesion may be present which is surgically curable..$^{[45]}$

MRI is the diagnostic method of choice, showing a starburst pattern of white matter veins converging on a large draining vein in the case of a venous malformation. ${ }^{[49]}$ When cerebral DVAs present symptoms such as cerebral hemorrhage, epilepsy, headache, cranial nerve paresis, and/or cerebral ataxia, surgical intervention has been carried out. ${ }^{[37,50-53]}$ Clinicians should be aware that, though generally benign, DVAs and their associated lesions may represent a complex entity 
with potential for clinical complication requiring, in certain cases, additional imaging investigations and specific medical management. ${ }^{[54,55]}$

\section{Conclusion}

A cavernous angioma was found more frequently in our patients with SE. However, DVAs were diagnosed in $46.9 \%$ of patients. Association localization of DVAs with localizationrelated epileptic seizures was observed in $60.0 \%$ of cases.

Thus, DVAs as a cause of seizures are important to consider when examining patients with epileptic seizures. The inclusion of SWI in the protocol of neuroradiological studies has allowed us to improve the quality of diagnostic care for patients with symptomatic focal epilepsy in our clinic, and it was useful in the selection of surgical treatment for drugresistant forms of epilepsy.

\section{Acknowledgements}

We thank all the members of the Neurological Center Epileptology, Neurogenetics and Brain Research at the University Clinic for their kind assistance.

\section{Competing interests}

The authors declare that they have no competing interests.

\section{References}

1. Truwit CL. Venous angioma of the brain: history, significance, and imaging findings. AJR Am J Roentgenol. 1992; 159:1299-307.

2. Ostertun B, Solymosi L. Magnetic resonance angiography of cerebral developmental venous anomalies: its role in differential diagnosis. Neuroradiology. 1993; 35:97-104.

3. Zimmer A, Hagen T, Ahlhelm F, Viera J , Reith W, Schulte-Altedorneburg G. Developmental venous anomaly (DVA). Radiologe. 2007; 47(10):868, 870-4.

4. Jones BV, Linscott L, Koberlein G, Hummel TR, Leach JL. Increased prevalence of developmental venous anomalies in children with intracranial neoplasms. AJNR Am J Neuroradiol. 2015; 36 (9):1782-5.

5. Koc K, Anik I, Akansel Q, Anik Y, Ceylan S. Massive intracerebral haemorrage due to developmental venous anomaly. Br J Neurosurg. 2007; 21:403-5.

6. Uchino A, Hasuo K, Matsumoto S, Fujii K, Fukui M, Horino K, et al. Cerebral venous angiomas associated with hemorrhagic lesions. Their MRI manifestations. Clin Imaging. 1996; 20:157-63.

7. Baumann CR, Schuknecht B, Lo Russo G, Cossu M, Citterio A, Andermann F, et al. Seizure outcome after resection of cavernous malformations is better when surrounding hemosiderin-stained brain also is removed. Epilepsia. 2006; 47:563-6.

8. Upchurch K, Stern JM, Salamon N, Dewar S, Engel $\mathrm{J}$ Jr, Vinters HV, et al. Epileptogenic temporal cavernous malformations: Operative strategies and postoperative seizure outcomes. Seizure. 2010; 19 (2):120-8.

9. Morioka T, Hashiguchi K, Nagata S, Miyagi Y, Yoshida F,
Mihara F, et al. Epileptogenicity of supratentorial medullary venous malformation. Epilepsia. 2006; 47:365-70.

10. Lee C, Pennington MA, Kenney CM 3rd. MR evaluation of developmental venous anomalies: medullary venous anatomy of venous angiomas. AJNR Am J Neuroradiol. 1996; 17:61-70

11. Lee BC, Vo KD, Kido DK, Mukherjee P, Reichenbach $\mathrm{J}$, Lin W, et al. MR high-resolution blood oxygenation leveldependent venography of occult (low-flow) vascular lesions. AJNR Am J Neuroradiol. 1999. 20(7):1239-42.

12. Zhu WZ, Qi JP, Zhan CJ, Shu HG, Zhang L, Wang CY, et al. Magnetic resonance susceptibility weighted imaging in detecting intracranial calcification and hemorrhage. Chin Med J. 2008; 121(20):2021-5.

13. Shnayder NA, Dmitrenko DV, Sadykova AV, Sharavii LK, Shulmin AV, Shapovalova EA, et al. Epidemiological studies on epilepsy in Siberia. Medical and Health Science Journal. 2011; 6:35-42.

14. Dmitrenko DV, Shnayder NA, Kiselev IA, Shulmin AV, Zhirova NV, Shapovalova EA, et al. Problems of rational therapy for epilepsy during pregnancy. Open Journal of Obstetrics and Gynecology. 2014; 4:506-15.

15. Striano S, Nocerino C, Striano P, Boccella P, Meo R, Bilo L, et al. Venous angiomas and epilepsy. Neurol Sci. 2000; 21: $151-5$.

16. Awad IA, Robinson JR Jr, Mohanty S, Estes ML. Mixed vascular malformations of the brain: Clinical and pathogenic considerations. Neurosurgery. 1993; 33:179-88.

17. Naff NJ, Wemmer J, Hoenig-Rigamonti K, Rigamonti DR. A longitudinal study of patients with venous malformations: Documentation of a negligible hemorrhage risk and benign natural history. Neurology. 1998; 50:1709-14.

18. Abdulrauf SI, Kaynar MY, Awad IA. A comparison of the clinical profile of cavernous malformations with and without associated venous malformations. Neurosurgery. 1999; 44: 41-6, discussion 46-7.

19. Chandra PS, Manjari T, Chandramouli BA, Jayakumar PN, Shankar SK. Cavernous-venous malformation of brain stem: Report of a case and review of literature. Surg Neurol. $1999 ; 52: 280-5$.

20. Wurm G, Schniyer M, Fellner FA. Cerebral cavernous malformations associated with venous anomalies: surgical considerations. Neurosurgery. 2005; 57 (1 Suppl):42-58.

21. Sarwar K, McCormick WF. Intracerebral venous angioma. Case report and review. Arch Neurol. 1978; 35:323-5.

22. Pereira VM, Geibprasert S, Krings T, Aurboonyawat T, Ozanne A, Toulgoat F, et al. Pathomechanisms of symptomatic developmental venous anomalies. Stroke. 2008; 39:3201-15. 23. Tomycz ND, Vora NV, Kanal E, Horowitz MB, Jovin TG. Intracranial arterialized venous angioma: case report with new insights from functional brain MRI. Diagn Interv Radiol. 2010; 16:13-5.

24. San Millán Ruíz D, Delavelle J, Yilmaz H, Gailloud P, Piovan E, Bertramello A, et al. Parenchymal abnormalities associated with developmental venous anomalies. Neuroradiology 2007; 49:987-95.

25. Rammos SK, Maina R, Lanzino G. Developmental venous anomalies: current concepts and implications for management. Neurosurgery. 2009; 65:20-9; discussion 29-30.

26. Saito Y, Kobayashi N. Cerebral venous angiomas: clinical evaluation and possible etiology. Radiology. 1981; 139:87-94. 27. Hong Y, Chung T-S, Suh S, Park CH, Tomar G, Seo KD, et al. The angioarchitectural factors of the cerebral developmental 
venous anomaly; can they be the causes of concurrent sporadic cavernous malformation? Neuroradiology. 2010; 52:883-91. 28. Ruíz DSM, Yilmaz H, Gailloud P. Cerebral developmental venous anomalies: current concepts. Ann Neurol. 2009; 66(3): 271-83.

29. Lasjaunias P, Burrows P, Planet C. Developmental venous anomalies (DVA): the so-called venous angioma. Neurosug Rev. 1986; 9:233-44.

30. Saito Y, Kobayashi N. Cerebral venous angiomas: clinical evaluation and possible etiology. Radiology. 1981; 139:87-94. 31. Wilson CB Cryptic vascular malformations. Clin Neurosurg. 1992; 38:49-84.

32. Gallione CJ, Pasyk KA, Boon LM, Lenno F, Johnson DW, Helmbold E,et al. A gene for familial venous malformations maps to chromosome $9 \mathrm{p}$ in a second large kindred. J Med Genet. 1995; 32:197-9.

33. Valavanis A, Wellauer J, Yasargil MG. The radiological diagnosis of cerebral venous angioma: cerebral angiography and computed tomography. Neuroradiology. 1983; 24:193-9. 34. Pryor J, Setton A, Berenstein A. Venous anomalies and associated lesions. Neurosurg Clin N Am. 1999; 10:519-25.

35. Garner TB, Del Curling O Jr, Kelly DL Jr, Laster DW. The natural history of intracranial venous angiomas. J Neurosurg. $1991 ; 75: 715-22$.

36. Kondziolka D, Dempsey PK, Lunsford L.D. The case of conservative management of venous angiomas. Can J Neurol Sci. 1991; 18:295-9.

37. Handa H, Moritake K. Venous angioma of the brain. In: Fein JM, Flamm ES. Cerebrovascular Surgery. Vol. IV. Springer, New York, 1985:1139-49.

38. Hon JM, Bhattacharya JJ, Counsell CE, Papanastassiou $\mathrm{V}$, Ritchie V, Roberts RC, et al. The presentation and clinical course of intracranial developmental venous anomalies in adults: a systematic review and prospective, population-based study. Stroke. 2009; 40:1980-5.

39. Topper R, Jurgens E, Reual J, Thron A. Clinical significance of intracranial developmental venous anomalies. J Neurol Neurosurg Psychiatry. 1999; 67:234-8.

40. Lo S, Cheung Y, Tang K, Chan C, Siu C, Kwok K, et al. Non-haemorrhagic Pontine Venous Infarct due to Thrombosed Cerebellar Venous Angioma. J HK Coll Radiol. 2009; 12:79-84. 41. McLaughlin MR, Kondziolka D, Flickinger JC, Lunsford S, Lunsford LD. The prospective nature history of cerebral venous malformations. Neurosurg. 1998; 43:195-201.

42. Griffiths D, Newey A, Faulder K, Steinfort B, Krause M.
Thrombosis of a Developmental Venous Anomaly Causing Venous Infarction and Pontine Hemorrhage. J Stroke Cerebrovasc Dis. 2013; 22:653-5.

43. Vaitkevicius H, Erdemli HE, Anderson WS, Zamani AA, Friedlander RM, Folkerth RD. Biopsy neuropathology of cerebral ischemia associated with a developmental venous anomaly. Clin Neurol Neurosurg. 2013; 115:621-3.

44. Numaguchi Y, Kitamura K, Fukui M, Ikeda J, Hasuo K, Kishikawa T, et al. Intracranial venous angiomas. Surg Neurol. 1982; 18:193-202.

45. Fuji M, Kitahara T, Moroi J, Kato S, Ito H. Temporal lobe epilepsy associated with cerebral venous angioma-case report. Neurol Med Chir. 1998; 38:413-6.

46. Agnoli AL, Hildbrandt G. Cerebral venous angiomas. Acta Neurochir. 1985; 78:4-12.

47. Sohail A, Xiong Z, Qureshi MH, Qureshi AI. Complex Partial Epilepsy Associated with Temporal Lobe Developmental Venous Anomaly. J Vasc Interv Neurol. 2015; 8:24-7.

48. Scheidegger O, Wiest R, Jann K, König T, Meyer K, Hauf M. Epileptogenic developmental venous anomaly: insights from simulataneous EEG/fMRI. Clin EEG Neurosci. 2013; 44:157-60.

49. Dănăilă L. The venous malformations of the brain. Proc Rom Acad, Series B. 2013; 15:14-33.

50. Biller J, Toffol GJ, Shea JF, Fine M, Azar-Kia B. Cerebral venous angiomas. A continuing controversy. Arch Neurol. $1985 ;$ 42:367-70.

51. Bitoh S, Hasegawa H, Fujiwara M, Sakurai M. Angiographically occult vascular malformations causing intracranial hemorrhage. Surg Neurol. 1982; 17:35-42.

52. Kramer RA, Wing SD. Computed tomography of angiographically occult cerebral vascular malformations. Radiology. 1977; 123:649-52.

53. Pak H, Patel SC, Malik GM, Ausman JI. Successful evacuation of a pontine hematoma secondary to rupture of a venous angioma. Surg Neurol. 1981; 15:164-7.

54. Cohen JE, Boitsova S, Moscovici S, Itshayek E. Concepts and controversies in the management of cerebral developmental venous anomalies. Isr Med Assoc J. 2010; 12: 703-6.

55. Meng G, Bai C, Yu T, Wu Z, Liu X, Zhang J, et al. The association between cerebral developmental venous anomaly and concomitant cavernous malformation: an observational study using magnetic resonance imaging. BMC Neurol. 2014; 15:14-50. 